\title{
Noncardiac Chest Pain: Epidemiology, Natural Course and Pathogenesis
}

\author{
Ronnie Fass ${ }^{1 *}$ and Sami R Achem ${ }^{2}$ \\ ${ }^{1}$ Section of Gastroenterology, Department of Medicine, Southern Arizona VA Health Care System, Tucson, Arizona, USA, ${ }^{2}$ Mayo College of \\ Medicine, Mayo Clinic, Jacksonville, Florida, USA
}

Noncardiac chest pain is defined as recurrent chest pain that is indistinguishable from ischemic heart pain after a reasonable workup has excluded a cardiac cause. Noncardiac chest pain is a prevalent disorder resulting in high healthcare utilization and significant work absenteeism. However, despite its chronic nature, noncardiac chest pain has no impact on patients' mortality. The main underlying mechanisms include gastroesophageal reflux, esophageal dysmotility and esophageal hypersensitivity. Gastroesophageal reflux disease is likely the most common cause of noncardiac chest pain. Esophageal dysmotility affects only the minority of noncardiac chest pain patients. Esophageal hypersensitivity may be present in non-GERD-related noncardiac chest pain patients regardless if esophageal dysmotility is present or absent. Psychological co-morbidities such as panic disorder, anxiety, and depression are also common in noncardiac chest pain patients and often modulate patients' perception of disease severity.

(J Neurogastroenterol Motil 2011;17:110-123)

Key Words

Chest pain; Esophageal motility disorders; Esophagus; Heartburn

\section{Introduction}

Noncardiac chest pain (NCCP) is very common in the general population; however, a patient's history and characteristics do not reliably distinguish between cardiac and esophageal causes of chest pain. ${ }^{1,2}$ When it comes to chest pain, the cardiologist's first priority is to exclude any acute life-threatening cardiovascular condition. ${ }^{3}$ These include acute coronary syndrome, aortic dissection, pulmonary thromboembolism, and pericardial tamponade. If these acute conditions have been excluded, evalua- tion for chronic ischemic heart disease or pericardial disease must be pursued. Various tests can help determine the presence and severity of ischemia, left ventricular function, appearance of the coronary arteries, and functional capacity. They include exercise test electrocardiogram, echocardiography or nuclear single photon emission computed tomography (SPECT) and, if patients are unable to exercise, pharmacologic echocardiography, nuclear SPECT or cardiac MRI. The decision about which tests to pursue should be left to the discretion of the treating cardiologist. ${ }^{4}$ The heightened awareness about the potentially devastating ramifications of chest pain may drive patients to seek further medical

Received: February 11, 2011 Revised: March 17, 2011 Accepted: March 28, 2011

(c) This is an Open Access article distributed under the terms of the Creative Commons Attribution Non-Commercial License (http://creativecommons. org/licenses/by-nc/3.0) which permits unrestricted non-commercial use, distribution, and reproduction in any medium, provided the original work is properly cited.

*Correspondence: Ronnie Fass, MD

Professor of Medicine, University of Arizona, Chief of Gastroenterology, Southern Arizona VA Health Care System, 3601 South Sixth Avenue (1-111-GI), Tucson, AZ 85723-0001, USA

Tel: +1-520-792-1450 (or 5139), Fax: +1-520-629-4737, E-mail: Ronnie.Fass@va.gov

Financial support: None.

Conflicts of interest: None. 
attention despite a negative cardiac workup.

Compared to patients with cardiac angina, those with NCCP are usually younger, less likely to have typical symptoms, and more likely to have a normal resting electrocardiogram. ${ }^{6}$ Additionally, levels of anxiety of NCCP patients seen in a rapid access chest pain clinic significantly exceeded those of patients with cardiac angina and remained above community norms for at least 2 months after clinic visit. ${ }^{7}$ NCCP patients view their condition as significantly less controllable and less understandable than those whose pain is of cardiac origin. ${ }^{8}$

NCCP may be the manifestation of gastrointestinal (GI) or non-GI-related disorders. An important step toward understanding the underlying mechanisms of NCCP was the recognition that gastroesophageal reflux disease (GERD) is the most common contributing factor for chest pain. While chest pain has been considered an atypical manifestation of GERD, it is an integral part of the limited repertoire of esophageal symptoms. In patients with non-GERD related NCCP, esophageal motility disorders, and functional chest pain (FCP) of presumed esophageal origin are the main underlying mechanisms for symptoms. The Rome III Committee does not specifically address NCCP but rather a subset of patients with NCCP termed "functional chest pain of presumed esophageal origin" to describe recurrent episodes of substernal chest pain of visceral quality with no apparent explanation. As with all other functional esophageal disorders, GERD and esophageal dysmotility should also be ruled out before the diagnosis is established. ${ }^{9}$ However, up to $20 \%$ of patients with FCP exhibit other functional disorders, primarily irritable bowel syndrome (27\%) and abdominal bloating (22\%). ${ }^{10}$

\section{Definition}

Noncardiac chest pain is defined as recurrent chest pain that is indistinguishable from ischemic heart pain after a reasonable workup has excluded a cardiac cause.

Patients with NCCP may report squeezing or burning substernal chest pain, which may radiate to the back, neck, arms and jaws, and is indistinguishable from cardiac related chest pain. This is compounded by the fact that patients with history of coronary artery disease (CAD) may also experience NCCP. Consequently, all NCCP patients should first undergo evaluation by a cardiologist to exclude cardiac angina. ${ }^{11,12}$ Differentiating on a clinical basis only between cardiac angina and NCCP has been shown to be a very difficult task. ${ }^{1}$ Furthermore, NCCP patients tend to report a higher rate of chest pain occurrence and greater pain intensity. They also more use commonly sensory and affective words than patients with ischemic heart disease. ${ }^{1}$ For the cardiologist, any two of the following clinical characteristics are suggestive of atypical cardiac angina and only one or none of these characteristics is indicative of NCCP: (1) substernal chest discomfort, pressure or heaviness that lasts several minutes, (2) pain induced by exertion, emotion, exposure to cold or a large meal and (3) pain that is relieved by rest or nitroglycerine usually signify cardiac angina. ${ }^{3}$

When it comes to chest pain, the cardiologist's first priority is to exclude any acute life threatening cardiovascular condition. ${ }^{3}$ These include acute myocardial infarction, unstable angina, aortic dissection, pulmonary thromboembolism and pericardial tamponade. If an acute cardiac syndrome has been excluded, then evaluation for chronic ischemic heart disease or pericardial disease should be pursued. Various tests can help determine the presence and severity of ischemia, left ventricular function, appearance of the coronary arteries and functional capacity. They include exercise electrocardiogram or exercise echocardiography, echocardiography or nuclear SPECT and, if patients are unable to exercise, pharmacologic (dobutamine, persantine or adenosine) echocardiography, nuclear SPECT or cardiac MRI. The decision of which tests to pursue should be left to the discretion of the treating cardiologist. ${ }^{4}$ A recent, population-based cohort study with nested case-control analysis demonstrated that patients with chest pain but without established ischemic heart disease had an increased risk of being diagnosed with ischemic heart disease (hazard ratio, 18.2; 95\% CI, 11.6 to 28.6) in the year after the index event of chest pain. ${ }^{13}$

We did not include frequency or severity of chest pain in our definition, because there is no clear spectrum or threshold of both clinical parameters in the literature. As a result, any attempt to limit the frequency and/or severity of chest pain may exclude many true sufferers with NCCP.

There are many causes for NCCP, and they are not limited to the esophagus (Table 1). Thus, the term NCCP is more inclusive and includes musculoskeletal, pulmonary, cardiovascular, infectious, drug-related, psychological and other GI disorders. ${ }^{14}$ Our focus in these guidelines will be only on esophageal-related mechanisms for NCCP. The Rome Criteria do not specifically address NCCP but rather a subset of patients with NCCP termed FCP of presumed esophageal origin. ${ }^{9}$ These are patients with recurrent episodes of substernal chest pain of visceral quality with no apparent explanation using currently available tests. 
Table 1. Common Noncardiac, Nonesophageal Etiologies for Chest Pain

Musculoskeletal

Tietze's syndrome

Costochondritis

Fibromyalgia

Precordial catch syndrome

Slipping rib syndrome

Gastrointestinal

Gastric

Biliary tree

Pancreatic

Intra-abdominal masses (benign and malignant)

Pulmonary

Pneumonia

Pulmonary embolus

Lung cancer

Sarcoidosis

Pneumothorax and pneumomediastinum

Pleural effusions

Intrathoracic masses (benign and malignant)

Miscellaneous

Aortic disorders

Pericarditis and myocarditis

Pulmonary hypertension

Herpes zoster

Drug-induced pain

Sickle cell crisis

Psychological disorders

\section{Epidemiology}

Noncardiac chest pain is a prevalent disorder resulting in high healthcare resource utilization and significant work absenteeism.

Information about the epidemiology of NCCP in the United States and around the world is relatively limited. Presently, chest pain is the second most common presentation to hospital emergency departments; however, only $25 \%$ of individuals who experience chest pain actually present to a hospital. ${ }^{15}$

The mean annual prevalence of NCCP in 6 populationbased studies was approximately 25\%. However, these studies differ in many aspects such as NCCP definition, geography, sample size, sampling order and ethnic disparities. ${ }^{16}$ A population-based survey in the United States assessed the prevalence of GERD in Olmsted County, Minnesota and reported an overall NCCP prevalence of $23 \% .^{17}$ Gender distribution among NCCP patients was similar (24\% among males and 22\% among females). Using the Rome criteria for functional GI disorders, Drossman et $\mathrm{al}^{18}$ reported a prevalence of $13.6 \%$ in 8,250 households in the United States. In this study, FCP of presumed esophageal origin was diagnosed rather than NCCP. Eslick et $\mathrm{al}^{19,20}$ recently evaluated the prevalence of NCCP in Australia by using a mailing of a validated Chest Pain Questionnaire to 1,000 randomly selected individuals. The study demonstrated a prevalence rate of $33 \%$ with almost equal gender distribution (32\% in males versus $33 \%$ in females). This study also showed that the population prevalence of NCCP decreases with increasing age. $^{19,20}$

A nationwide population-based study from South America found that the annual prevalence of NCCP was $23.5 \%$ and that NCCP has been equally reported by both sexes. ${ }^{21}$ In this study, frequent typical GERD symptoms (at least once a week) were significantly and independently associated with NCCP. Another recently published epidemiologic study demonstrated that the annual prevalence of NCCP in a Chinese population was $19 \% .^{22}$

Although females with NCCP tend to consult healthcare providers more often than men, the disorder affects both sexes equally. ${ }^{17,19,21}$ Additionally, females are more likely to present to hospital emergency departments with NCCP than males, but there are no sex differences regarding chest pain intensity. ${ }^{23}$ Overall, women tend to use terms like "burning" and "frightening" more often than men. ${ }^{24}$

Epidemiologic studies report a decrease in the prevalence of NCCP with increasing age. Women under 25 years of age and those between 45 and 55 years of age have the highest prevalence rates. $^{20}$ Patients with NCCP are younger, consume greater amounts of alcohol and tobacco, and are more likely to suffer from anxiety than their counterparts with ischemic heart disease. Patients with NCCP continue to seek treatment on a regular basis after the diagnosis was established for both chest pain and other unrelated symptoms, but few are in contact with hospital services. $^{25}$

In 1 study, almost a fourth of individuals with NCCP had sought healthcare for chest pain within the previous 12 months. None of the GI (heartburn, dysphagia and acid regurgitation) or psychological (anxiety, depression and neuroticism) risk factors was significantly associated with pursuing consultation for $\mathrm{NCCP}^{20}$

A recent US-based survey revealed that cardiologists manage by themselves about half of the patients who are diagnosed with $\mathrm{NCCP}^{26}$ Of those NCCP patients who were referred, $45.9 \%$ were sent back to the primary care physician (PCP), and only $29.3 \%$ to a gastroenterologist. In a survey of PCPs, Wong et $\mathrm{al}^{27}$ demonstrated that most NCCP patients were diagnosed and treated by PCPs $(79.5 \%)$ without being referred to a gastroenterologist. The most preferred subspecialty for the initial di- 
agnostic evaluation of a patient presenting with chest pain was cardiology (62\%), followed by gastroenterology (17\%). The mean percentage of such referrals was only $22 \%$. The most preferred subspecialty for further management of $\mathrm{NCCP}$ was gastroenterology (76\%), followed by cardiology (8\%). The mean percentage of the actual referral rate was $29.8 \%$ for gastroenterologists and $14 \%$ for cardiologists. ${ }^{27}$

A study by Eslick and Talley ${ }^{28}$ reported that $78 \%$ of patients who presented to a hospital emergency department with acute chest pain had seen a healthcare provider in the last 12 months. The most common healthcare provider seen was a general practitioner $(85 \%)$, followed by cardiologist $(74 \%)$, gastroenterologist (30\%), pulmonologist (14\%), alternative therapist (8\%) and psychologist (10\%). ${ }^{28}$ A multiple logistic regression analysis revealed that patients with chest pain who are also suffering from heartburn were 16 times more likely to see a general practitioner (OR, $16.40 ; 95 \% \mathrm{CI}, 1.98-135.99)$ and 3 times more likely to consult a gastroenterologist (OR, 3.10; 95\% CI, 1.26-7.62). Additionally, work absenteeism rates (29\%) and interruptions to daily activities (63\%) were high because of NCCP.

Many patients with NCCP report poor quality of life and admit taking cardiac medications despite lack of evidence for a cardiac cause. Only a small fraction of patients feel reassured. Consequently, the economic burden of the disease has been proposed to be very high, although studies evaluating the cost impact of NCCP on the healthcare system are very scarce. In 1 study, the healthcare cost for NCCP was estimated to be more than $\$ 315$ million annually, primarily because of multiple clinic visits, emergency room visits, hospitalizations and prescription medications. ${ }^{29}$ This cost estimate does not include indirect costs such as lost days of work or the impact of symptoms on patients' quality of life, which have been demonstrated to be more significant when evaluating the economic burden of patients with functional bowel disorders. In Australia, the annual cost associated with NCCP presentations to the Nepean Hospital amount to approximately a $\$ 1.4$ million. $^{30}$ The researchers extrapolated these costs to the Australian healthcare system and conservatively estimated that NCCP accounts for at least a $\$ 30$ million of the healthcare budget annually.

\section{Natural Course}

\section{Noncardiac chest pain is a chronic disorder that reduces patient's quality of life but has no impact on mortality.}

Thus far, very few studies have evaluated the natural course of NCCP. Obviously, the main concern is the likelihood of these patients developing true ischemic heart disease if followed long term. One of the early studies by Wielgosz et $\mathrm{al}^{31}$ followed 821 patients with chest pain and normal coronary arteries for a period of 1-year. The authors demonstrated that only $3(0.3 \%)$ patients died, and all were due to nonischemic reasons. ${ }^{31}$ However, most of the patients $(67 \%)$ continued to experience chest pain to some degree (39\% less pain, 26\% the same pain and 2\% more severe pain). In a study that followed $46 \mathrm{NCCP}$ patients over a period of 11 years, only $2(4.3 \%)$ of the subjects died from a cardiovascularrelated event (stroke and ischemic heart disease). Again, as in the previous study, $74 \%$ of the surviving NCCP patients continued to report chest pain 11 years later, and of those $34 \%$ reported chest pain symptoms weekly. ${ }^{32}$ Other studies also documented a very limited long-term mortality in NCCP patients but with continuous debilitating symptoms, impaired functional status, chronic use of drugs (GI, cardiac and psychiatric), repeated admissions to the hospital, and repeated cardiac and noncardiac procedures. ${ }^{25,33-37}$ In a survey study, 119 NCCP patients, of which 63 were diagnosed as having pain from the esophagus, were followed for a period of 21.8-month. ${ }^{38}$ Patients with esophageal-related chest pain usually continued to have recurrent pain. Interestingly, a specific diagnosis did not significantly increase the likelihood of pain resolution. However, patients who understood that the esophagus was the source of their pain were significantly less likely to feel disabled by their pain and therefore were less likely to require continued physician evaluation. This study was published prior to the proton pump inhibitor (PPI) era. It is unlikely that patients with NCCP due to GERD will continue to have symptoms long term if they are compliant with their antireflux treatment. In another study that compared long-term natural history between NCCP and GERD patients, the authors found no significant difference in survival between the 2 groups (hazard ratio, 1.1 ; $95 \% \mathrm{CI}, 0.8-1.5$ ). Interestingly, the diagnosis of $\mathrm{NCCP}$ disappeared from the electronic hospital record in $96 \%$ of the patients within 2 years of follow-up. ${ }^{39}$

In a recent study that followed $355 \mathrm{NCCP}$ patients, the authors demonstrated that $49 \%$ sought care in the emergency department, $42 \%$ underwent repeated cardiac workup, and only $15 \%$ were seen by a gastroenterologist. ${ }^{13}$ Survival free of cardiac death in the subset with NCCP and a GI disorder was $90.2 \%$ at 10 years and $84.8 \%$ at 20 years, compared to $93.7 \%$ at 10 years and $88.1 \%$ at 20 years for those with NCCP of unknown origin.

Less than a handful of studies reported similar mortality between patients with NCCP and those with CAD. ${ }^{37,40}$ A more re- 
cent study by Eslick and Talley ${ }^{41}$ followed 126 NCCP and 71 cardiac patients who were seen in the emergency room for a period of 4-year. The majority of the $\operatorname{NCCP}(71 \%)$ and the CAD patients $(81 \%)$ continued to have symptoms 4 years later. The authors found no difference in the mortality rate between the 2 groups (CAD-11.0\% vs NCCP-5.5\%, $P=0.16$ ). However, the study may suffer from type II error, and the results need to be confirmed in a larger cohort of patients.

Overall, the aforementioned data support the overall conclusion that increased mortality is uncommon in NCCP patients. However, patients with NCCP demonstrate poor quality of life primarily due to continuation of symptoms many years after diagnosis.

\section{Pathogenesis}

\section{Gastroesophageal Reflux Disease}

Gastroesophageal reflux disease is the most common esophageal cause for noncardiac chest pain in patients with and without coronary artery disease.

Many studies have shown an association between GERD and NCCP. However, association does not confer causality. Resolution or improvement of chest pain symptoms in response to treatment with antireflux medications provides the missing causal link.

Locke et al and colleagues ${ }^{17}$ have demonstrated that NCCP is more commonly reported by patients $(37 \%)$ who experience heartburn symptoms at least weekly, as compared with $30.7 \%$ of those who have infrequent heartburn (less than once a week) and $7.9 \%$ of those without any GERD symptoms. In another community-based study, the authors found that $53 \%$ of all patients with NCCP experienced heartburn and $58 \%$ acid regurgitation. ${ }^{20}$ Stahl et $\mathrm{al}^{42}$ found in a small sample of NCCP patients that $61.5 \%$ had GERD-related symptoms. In 3 different studies evaluating the role of the PPI test in patients with NCCP, the authors found GERD-related symptoms in $68 \%-90 \%$ of the patients. $^{43-45}$

Ambulatory 24 hour esophageal $\mathrm{pH}$ testing studies have demonstrated that about half of NCCP patients have an abnormal esophageal acid exposure. Stahl et $\mathrm{al}^{42}$ evaluated 13 consecutive NCCP patients and found that $69.2 \%$ had an abnormal $\mathrm{pH}$ test. Beedassy et $\mathrm{al}^{46}$ evaluated 104 patients with $\mathrm{NCCP}$ and documented that $48 \%$ of them had an abnormal pH test. It should be noted that only $21 \%$ of the 52 patients who reported chest pain during the study had a concomitant acid reflux event. Interestingly, only 10 of the 52 subjects had a positive symptom index $(>50 \%)$. Similarly, DeMeester et $\mathrm{al}^{47}$ demonstrated that $46 \%$ of patients with chest pain had symptoms associated with an acid reflux event as documented during $\mathrm{pH}$ testing. Pandak et $\mathrm{al}^{48}$ found an abnormal $\mathrm{pH}$ test in $42 \%$ of NCCP patients. In 3 different studies evaluating the role of the PPI test, the authors found abnormal $\mathrm{pH}$ test in $37.5 \%-67 \%$ of the NCCP patients. ${ }^{43-45}$ In a study from Asia, $34.3 \%$ of the NCCP patients had at least 1 abnormal $\mathrm{pH}$ parameter. ${ }^{49}$ Even in patients with $\mathrm{CAD}$ who continued to have atypical chest pain symptoms, up to $67 \%$ had some of their painful episodes associated with acid reflux. ${ }^{50}$

The presence of esophageal mucosal abnormalities consistent with GERD appears to be less common in NCCP patients than GERD symptoms or excess esophageal acid exposure. From different studies, the range has been between $2.5 \%-75 \% .^{14,49,51,52}$ In 3 different studies evaluating the role of the PPI test in patients with NCCP, the authors found GERD-related endoscopic findings in $44 \%-75 \%$ of the NCCP patients. ${ }^{43-45}$ In all of these studies, low-grade erosive esophagitis was the main GERD-related endoscopic finding. A recent study by Dickman et $\mathrm{al}^{53}$ evaluated upper GI findings in patients with NCCP as compared with those having only GERD-related symptoms using a large multicenter consortium. Of the NCCP group, $28.6 \%$ had hiatal hernia, $19.6 \%$ erosive esophagitis, $4.4 \%$ Barrett's esophagus, and $3.6 \%$ esophageal stricture/stenosis (Table 2). The prevalence of these findings was significantly lower in the NCCP group when compared with the GERD group. From this study, it appears that GERD-related mucosal abnormalities are not uncommon in the esophagus of NCCP patients. However, the prevalence of these anatomical findings is lower than what has been observed in GERD patients. Importantly, NCCP patients may also demonstrate Barrett's esophagus, albeit uncommonly.

The mechanism by which gastroesophageal reflux causes NCCP remains poorly understood. It is still unclear why esophageal exposure to gastric content in some patients causes heartburn and in others chest pain. This is compounded by the fact that some patients may experience chest pain at 1 time and heartburn at other times.

Characteristics of the individual reflux episodes (duration and $\mathrm{pH}$ level) have been proposed to influence patients' symptoms. Smith et $\mathrm{al}^{54}$ studied 25 individuals with NCCP to determine the relation between the sensation of pain in GERD and $\mathrm{pH}$ of the refluxate. They found that all 25 patients had reproduction of their pain during intraesophageal infusion of sol- 
Table 2. The Value of Endoscopy in Noncardiac Chest Pain Patients From a Large Multicenter Consortium

\begin{tabular}{lccc}
\hline \multicolumn{1}{c}{ Findings } & $\begin{array}{c}\text { Chest pain group } \\
(\mathrm{n}=3,688)\end{array}$ & $\begin{array}{c}\text { Reflux group } \\
(\mathrm{n}=32,981)\end{array}$ & $P$-value \\
\hline Barrett's esophagus & $163(4.4 \%)$ & $3,016(9.1 \%)$ & $<0.0001$ \\
Esophageal inflammation & $715(19.4 \%)$ & $9,153(27.8 \%)$ & $<0.0001$ \\
Hiatal hernia & $1,053(28.6 \%)$ & $14,775(44.8 \%)$ & $<0.0001$ \\
Normal & $1,627(44.1 \%)$ & $12,801(38.8 \%)$ & $<0.0001$ \\
Stricture/stenosis & $132(3.6 \%)$ & $1,223(3.7 \%)$ & 0.69 \\
\hline
\end{tabular}

utions with $\mathrm{pH} 1$ and 1.5. Reflux events resulting in pain were significantly longer than those without pain and were more often associated with a recently preceding painful episode.

Different underlying mechanisms have been suggested to result in esophageal hypersensitivity in NCCP patients. These include peripheral sensitization of esophageal sensory afferents leading to heightened responses to physiologic and pathologic stimuli and modulation of afferent neural function at the level of the spinal dorsal root or the central nervous system. ${ }^{55}$ In 1 study, ${ }^{56}$ healthy subjects underwent perfusion of the distal esophagus with normal saline or $0.1 \mathrm{~N}$ hydrochloric acid. Perceptual responses to intraluminal esophageal balloon distension were evaluated using electronic barostat. As compared with saline, acid perfusion reduced the perception threshold (innocuous sensation) and tended to reduce the pain threshold (aversive sensation). This study demonstrated short-term sensitization of mechanosensitive afferent pathways by transient exposure to acid. The authors suggested that in patients with NCCP, acid reflux induces sensitization of the esophagus, which may subsequently alter the way the esophagus perceives otherwise normal esophageal distentions. Sarkar et $\mathrm{al}^{57}$ recruited 19 healthy volunteers and 7 patients with NCCP. Hydrochloric acid was infused into the distal esophagus over 30 minutes. Sensory responses to electrical stimulation were monitored within the acid-exposed distal esophagus and the non-exposed proximal esophagus before and after infusion. In the healthy subjects, acid infusion into the distal esophagus lowered the pain threshold in the upper esophagus. Patients with NCCP already had a lower resting esophageal pain threshold than healthy subjects. After acid perfusion, their pain threshold in the proximal esophagus fell further and for a longer duration than was the case for the healthy subjects. Additionally, there was a decrease in pain threshold after acid infusion in the anterior chest wall. This study demonstrated the development of secondary allodynia (visceral hypersensitivity to innocuous stimulus in normal tissue that is in proximity to the site of tissue in- jury) in the proximal esophagus by repeated acid exposure of the distal esophagus. The concurrent visceral and somatic pain hypersensitivity is most likely caused by central sensitization (an increase in excitability of spinal cord neurons induced by activation of nociceptive C-fibers in the area of tissue injury). The patients with NCCP demonstrated visceral hypersensitivity and amplified secondary allodynia in the esophagus.

Another explanation how GERD may cause chest pain was provided by studies using high-frequency, intraluminal ultrasonography. Balaban et $\mathrm{al}^{58}$ demonstrated a temporal correlation between sustained contractions of the esophageal longitudinal muscle and spontaneous as well as provoked esophageal chest pain. In a follow-up study, the authors suggested that the duration of sustained esophageal contraction determines the type of symptom perceived by patients. ${ }^{59}$ Heartburn was associated with shorter duration contractions, whereas chest pain was associated with contractions of longer duration. In a recent study, the authors suggested that esophageal muscle thickness per se, in the absence of esophageal motility abnormality, can lead to chest pain symptoms. $^{60}$

Studies have demonstrated that NCCP patients with evidence of GERD (endoscopic findings and/or abnormal $\mathrm{pH}$ test) commonly respond to antireflux treatment. Between $78 \%-92 \%$ of NCCP patients with objective evidence of GERD demonstrated symptoms improvement on antireflux treatment. ${ }^{43,45,48,49}$ In contrast, response to PPI treatment in NCCP patients without objective evidence of GERD ranged between $10 \%$ and $14 \% .{ }^{43-45}$ It Kushnir et $\mathrm{al}^{61}$ have demonstrated that a positive symptom-association probability and elevated acid exposure time predicted response to PPI treatment in patients with NCCP. When used hierarchically, response to antireflux treatment was best predicted when GERD parameters (acid exposure time, symptom-association probability and symptom index) were all abnormal and poorest when all normal. These data suggest a causal relationship between patients' GERD and chest pain symptoms.

\section{Esophageal Motility}

Only the minority of patients with noncardiac chest pain demonstrate esophageal motility abnormalities.

Several large studies demonstrated that approximately $30 \%$ of NCCP patients had abnormal esophageal manometry. ${ }^{62-64}$ In 1 study that included $910 \mathrm{NCCP}$ patients, the authors found that $70 \%$ had normal esophageal motility. ${ }^{62}$ Nutcracker esophagus (14.4\%) was the most commonly documented esophageal motility abnormality, followed by nonspecific esophageal motor dis- 
order $(10.8 \%)$. Diffuse esophageal spasm, achalasia and hypertensive lower esophageal sphincter were very uncommon in this NCCP group. In another study, Dekel et $\mathrm{al}^{63}$ evaluated 140 NCCP patients using the Clinical Outcomes Research Initiative database. Unlike the previous study that included patients from 1 major center with interest in esophageal motility, the study by Dekel et $\mathrm{al}^{63}$ included patients from more than 60 academic, Veteran Affairs, and private centers from around the United States. The authors also found that $70 \%$ of the subjects had a normal esophageal motility test. Hypotensive lower esophageal sphincter $(61 \%)$ was the most common motility abnormality diagnosed, followed by hypertensive lower esophageal sphincter, nonspecific esophageal motor disorder and nutcracker esophagus (10\% each). In this study, achalasia and diffuse esophageal spasm were also very uncommon. The difference in the distribution of motility abnormalities between the 2 studies reflects the different study designs. In the first study, only non-GERD-related NCCP patients were included, whereas all newcomers were enrolled into the second study. A recent study from Chile evaluated 100 newly diagnosed NCCP patients and found that $8 \%$ of them had an abnormal esophageal manometry. ${ }^{65}$ In this study, $36 \%$ of patients had nutcracker esophagus, $28 \%$ hypotensive lower esophageal sphincter, and $16 \%$ nonspecific esophageal motor disorder. The reason for the discrepancy between the results of this study and the other 2 is unclear. It appears, however, that the high rate of esophageal motility abnormalities recorded in NCCP patients in this study may reflect a local referral bias.

The relationship between NCCP and esophageal dysmotility remains an area of intense controversy because documentation of esophageal dysmotility during manometry is rarely associated with reports of chest pain symptoms. ${ }^{2}$ In addition, unlike GERD we are still devoid of highly effective pharmacologic compounds that can eliminate esophageal dysmotility and thus can be used to demonstrate a causal relationship. ${ }^{66}$ Furthermore, in NCCP patients who underwent simultaneous esophageal manometry and pH testing, chest pain was more commonly associated with acid reflux events than motility abnormalities. ${ }^{64,67}$ Even the past usage of ambulatory 24 hour esophageal manometry was unable to improve the sensitivity of the test in NCCP. In fact, studies have demonstrated that $27 \%-43 \%$ of patients did not report any chest pain symptoms during the test. ${ }^{64,68}$ Moreover, the investigators were able to relate pain episodes to recorded esophageal dysmotility in only $13 \%-24 \%$ of patients. Consequently, the routine usage of ambulatory 24 hour esophageal manometry has been questioned, and the technique is rarely performed in clinical practice.
In 1 study, the authors were able to demonstrate improvement of NCCP symptoms in patients with nutcracker esophagus receiving antireflux treatment but with no effect on esophageal motility. ${ }^{69}$

Some authorities have proposed using esophageal motility abnormalities in NCCP patients as a marker for an underlying motor disorder that may be responsible for patients' symptoms. ${ }^{70}$ However, it is plausible that our current evaluative techniques of the esophagus provide only crude information about esophageal motor function. Future tests will require providing a more comprehensive evaluation of anatomical structure and biomechanics of the esophagus and their relationship to pain.

\section{Esophageal Hypersensitivity}

\section{Esophageal hypersensitivity has been demonstrated in most of the non-gastroesophageal reflux disease-related noncardiac chest pain patients, regardless if esophageal dysmotility is present or absent.}

Studies have consistently documented alteration in pain perception regardless of whether dysmotility was present or absent in patients with NCCP.

Visceral hypersensitivity is a phenomenon in which conscious perception of visceral stimulus is enhanced independently of the intensity of the stimulus. ${ }^{55}$ Peripheral and central mechanisms have been proposed to be responsible for visceral hypersensitivity in patients with NCCP. It has been hypothesized that peripheral sensitization of esophageal sensory afferents leads to subsequently heightened responses to physiologic or pathologic stimuli of the esophageal mucosa. ${ }^{55}$ Additionally, central sensitization at the brain level or the dorsal horn of the spinal cord may modulate afferent neural function and thus enhance perception of intraluminal stimuli. ${ }^{71}$ What causes peripheral or central sensitization remains to be determined. Studies have shown that acute tissue irritation results in subsequent peripheral and central sensitization, which is manifested as increased background activity of sensory neurons, lowering of nociceptive thresholds, changes in stimulus response curves and enlargement of receptive fields. ${ }^{72}$ Peripheral sensitization involves the reduction of esophageal pain threshold and increase in the transduction processes of primary afferent neurons. ${ }^{73}$ Esophageal tissue injury, inflammation, spasm or repetitive mechanical stimuli can all sensitize peripheral afferent nerves. The presence of esophageal hypersensitivity can be subsequently demonstrated long after the original stimulus is no longer present and the esophageal mucosa has healed. However, it is still unclear what factors are pivotal for the persistence of 
such esophageal hypersensitivity.

Studies have demonstrated that patients with non-GERDrelated NCCP have lower perception thresholds for pain. Richter et $\mathrm{al}^{74}$ used balloon distension protocol in the distal esophagus and found that $50 \%$ of patients with $\mathrm{NCCP}$ developed pain at volumes of $8 \mathrm{~mL}$ or less in comparison with $9 \mathrm{~mL}$ or more in healthy subjects who developed pain. The authors found no difference in the pressure-volume curve of the 2 groups as well as no difference in esophageal motility. ${ }^{74}$ When the balloon was inflated to $10 \mathrm{~mL}$, patients with a history of NCCP were more likely to experience pain (18/30) than the control subjects $(6 / 30){ }^{73}$ Barish et $\mathrm{al}^{73}$ evaluated 50 patients with $\mathrm{NCCP}$ and 30 healthy volunteers using graded balloon distension protocol. Of the patients with NCCP, 56\% (28/50) experienced their "typical" chest pain during balloon distension as compared with $20 \%$ (6/30) of the normal controls. ${ }^{73}$ Of those with NCCP who experienced pain, $85 \%$ reported pain at values below the usual sensory threshold $\left(20 \mathrm{~cm} \mathrm{H}_{2} \mathrm{O}\right){ }^{75}$ There was no difference in esophageal tone between the 2 groups.

Rao et $\mathrm{al}^{75}$ used impedance planimetry to evaluate 24 patients with NCCP and 12 healthy controls. Using balloon distention, they demonstrated that those with NCCP had lower perception thresholds for first sensation, moderate discomfort and pain in comparison to the healthy controls. ${ }^{75}$ Typical chest pain was reproduced in $83 \%$ of the NCCP patients. ${ }^{75}$ In addition, the reactivity of the esophagus to balloon distension was increased in those with NCCP, as was the pressure elastic modulus. Rao et $\mathrm{al}^{76}$ also performed graded balloon distensions of the esophagus using impedance planimetry in 16 consecutive patients with NCCP (normal esophageal evaluation) and 13 healthy control subjects. Patients who experienced chest pain during balloon distension were subsequently restudied after receiving intravenous atropine. Balloon distensions reproduced chest pain at lower sensory thresholds in most NCCP patients as compared with controls. Similar findings were documented after atropine administration despite relaxed and more deformable esophageal wall. Thus, the investigators concluded that hyperalgesia, rather than motor dysfunction, is the predominant mechanism for FCP.

Sarkar et $\mathrm{al}^{57}$ recruited 19 healthy volunteers and 7 patients with NCCP. Hydrochloric acid was infused into the distal esophagus during a period of 30-minute. Sensory responses to electrical stimulation were monitored within the acid-exposed distal esophagus and the non-exposed proximal esophagus both before and after infusion. In the healthy subjects, acid infusion into the distal esophagus lowered the pain threshold in the upper esophagus. Patients with NCCP already had a lower resting esophageal pain threshold than healthy subjects. After acid perfusion, their pain threshold in the proximal esophagus fell further and for a longer duration than in healthy subjects. Additionally, there was a decrease in the pain threshold of the anterior chest wall after acid infusion. This study demonstrated the development of secondary allodynia (visceral hypersensitivity to innocuous stimulus in normal tissue at proximity to site of tissue injury) in the proximal esophagus by repeated acid exposure of the distal esophagus. The concurrent visceral and somatic pain hypersensitivity is most likely caused by central sensitization (increase in excitability of spinal cord neurons induced by activation of nociceptive C-fibers in the area of the tissue injury). The patients with NCCP demonstrated both visceral hypersensitivity and amplified secondary allodynia in the esophagus. However, it is unclear from the study what mechanism is responsible for the exaggerated secondary allodynia and what initiates central sensitization in patients with NCCP. It is interesting to note that other studies in NCCP, using a similar human model of acute tissue irritation by acid infusion, showed no significant effect on pain thresholds. ${ }^{77}$

Börjesson et $\mathrm{al}^{77}$ also demonstrated that patients with NCCP have reduced sensitivity to esophageal balloon distension during simultaneous transcutaneous electrical nerve stimulation (TENS) as compared with healthy controls. ${ }^{78}$ This further supports the role of visceral hypersensitivity in NCCP and suggests that the phenomenon is probably due to central sensitization. ${ }^{79}$

Mehta et $\mathrm{al}^{79}$ also demonstrated that acid infusion into the distal esophagus reduces esophageal pain thresholds for balloon distension in patients with NCCP not previously sensitive to balloon distension or acid infusion.

In 1 study, subjects underwent perfusion of the distal esophagus with either normal saline or $0.1 \mathrm{~N}$ hydrochloric acid. ${ }^{56}$ Perceptual responses to intraluminal esophageal balloon distension using electronic barostat were recorded. Perfusion with acid was associated with a reduced sensation threshold (innocuous perception) and tended to reduce the pain threshold (aversive sensation). The study demonstrated short-term sensitization of mechanosensitive afferent pathways by transient exposure to acid. It was suggested that in patients with NCCP, acid reflux induces sensitization of the esophagus. This may subsequently alter the way in which otherwise normal esophageal distensions are perceived. ${ }^{80}$

Sarkar et $\mathrm{al}^{80}$ also evaluated 14 patients with GERD-related $\mathrm{NCCP}$ and 8 healthy controls. All subjects underwent an esoph- 
ageal electrical stimulation protocol in the proximal esophagus, and those with NCCP demonstrated lower perception thresholds for pain than normal controls. ${ }^{80}$ However, there was an increase in the perception thresholds for pain during electrical stimulation in the NCCP patients after a 6-week course of high-dose PPI (omeprazole $20 \mathrm{mg}$ twice daily). ${ }^{80}$ This study demonstrated that patients with NCCP and evidence of GERD have a component of esophageal hypersensitivity that is responsive to high-dose PPI therapy. ${ }^{80}$

In another small study that enrolled $22 \mathrm{NCCP}$ patients with documented nutcracker esophagus, the authors demonstrated that stepwise balloon distensions reproduced pain symptoms at a lower threshold in $90 \%$ of NCCP patients as compared with $20 \%$ of healthy controls. ${ }^{81}$ It was concluded that patients with NCCP and nutcracker esophagus also exhibit visceral hypersensitivity. Additionally, visceral hypersensitivity is the likely main underlying mechanism for patients' symptoms, rather than the presence of the high amplitude contractions (nutcracker esophagus). Unfortunately, the presence of GERD in these patients was not determined in this study.

In a recent study, $75 \%$ of patients with $\mathrm{FCP}$ who underwent impedance planimetry demonstrated esophageal hypersensitivity. ${ }^{82}$ These patients had larger cross-sectional areas, decreased esophageal wall strain, distensibility, and lower thresholds for perception, discomfort, and pain as compared with FCP patients without esophageal hypersensitivity or healthy controls. Another recent study showed that pain evoked by bag distention in FCP patients is dependent primarily on stress and to a lesser degree on strain. ${ }^{83}$ The pain does not appear to be related to mucosal perfusion.

\section{Psychological Comorbidity}

Psychological co-morbidities, such as panic disorder, anxiety and depression are common in noncardiac chest pain patients.

Psychological comorbidity has been shown to be common in NCCP and affects up to $75 \%$ of patients. ${ }^{84}$ It has yet to be determined if the high level of psychological comorbidity may be related to referral bias to tertiary referral centers or if it is the result of long-term experience of pain. Regardless, studies reported a high prevalence $(>50 \%)$ of panic disorder, anxiety and major depression in NCCP patients. ${ }^{20,84-97}$ Other psychological abnormalities have also been reported including neuroticism, hypochondriac behavior, obsessive-compulsive disorder, phobic disorder, and somatization. ${ }^{20,89-92,98-102}$ In a small study of 36 subjects with NCCP, the authors found that $58 \%$ had some type of psychological abnormality. ${ }^{103}$ Of those, anxiety, depression and panic disorder were the most common. In a large populationbased study in Australia, the authors surveyed a random sample of 1,000 residents in the Sydney area. ${ }^{20}$ Among those with NCCP, the prevalence of anxiety was $23 \%$ and depression $7 \%$. In a telephone survey from Hong Kong that included 2,209 subjects, the authors demonstrated that depression and anxiety were significantly more common in NCCP patients than those without NCCP. ${ }^{93}$

Among all esophageal symptoms, chest pain was shown to closely correlate with psychometric abnormalities. In some patients, chest pain is part of a host of symptoms that characterize panic attack. Panic attack is a common cause for emergency room visits due to chest pain. In a large study that encompassed 441 consecutive ambulatory patients presenting with chest pain to the emergency department of a heart center, $25 \%$ were diagnosed as suffering from a panic attack. ${ }^{104}$ Whilst the reason for the observed association between NCCP and panic disorder remains to be fully elucidated, hyperventilation was demonstrated to precipitate chest pain in $15 \%$ of patients with NCCP. ${ }^{104}$ Additionally, it was demonstrated that hyperventilation could provoke reversible esophageal manometric abnormalities such as esophageal spasm (4\%) and a nonspecific esophageal motor disorder (22\%). ${ }^{105}$ Furthermore, studies have demonstrated that hyperventilation may precipitate a panic attack.

Anxiety and depression influence reports of pain and thus contribute to the pathophysiology of NCCP. Lantinga et $\mathrm{al}^{106}$ found that patients with NCCP had higher levels of neuroticism and psychiatric comorbidity before and after cardiac catheterization than did patients with CAD. This finding appears to have prognostic significance because these patients display less improvement in pain, more frequent pain episodes, greater social maladjustment, and more anxiety at 1-year follow-up than individuals with relatively low initial levels of psychosocial disturbances. In a large epidemiological study from England, a significant relationship between NCCP and psychiatric disorders was demonstrated in young adults. ${ }^{107}$ Two independent variables were associated with chest pain: parental illness and fatigue during childhood.

Studies have been inconsistent when the frequency of panic disorder, anxiety, and depression were compared between NCCP patients and those with CAD. Some studies reported increased panic disorder, anxiety, and depression in NCCP patients, while others found no significant difference in the prevalence of psychological disorders between the 2 groups. ${ }^{100,108-110}$ In 1 study of 
199 participants, panic disorder was more common in NCCP as compared with those with CAD (41\% vs $22 \%) .{ }^{108}$ However, other psychiatric disorders were highly prevalent (72\%) but without any difference between the 2 groups. In contrast, Cormier et $\mathrm{al}^{111}$ demonstrated that $98 \mathrm{NCCP}$ patients scored higher on measures of anxiety and negative life events and had a significantly greater prevalence of DSM III panic disorder (47\% vs 6\%), major depression (39\% vs $8 \%$ ) and 2 or more simple phobias (43\% vs $12 \%$ ) than did patients with CAD. In a recent multivariate analysis, the authors were able to develop a predictive model for distinguishing between NCCP and CAD that includes alexithymia (a condition in which patients are unable to express their feelings with words), quality of life and coping based on religion and seeking medical help ( $85.4 \%$ sensitivity and $80.0 \%$ specificity). ${ }^{112}$

NCCP patients with psychological disorders show diminished quality of life, more frequent chest pain, and less treatment satisfaction than NCCP patients without psychological comorbidity. ${ }^{97}$ One study suggested that NCCP patients with more than 1 psychological disorder are more difficult to treat than those with a single psychological disorder. ${ }^{113}$

Cheng et $\mathrm{al}^{114}$ demonstrated that patients with NCCP, when compared to patients with rheumatism and healthy controls, tended to monitor more, use more problem-focused coping, display a coping pattern with a poorer strategy-situation fit and receive less emotional support in times of stress. Additionally, monitoring perceptual style and problem-focused coping were associated with higher levels of anxiety and depression. Jerlock et $\mathrm{al}^{115}$ evaluated 231 NCCP patients and compared their psychosocial profile with 1,069 healthy subjects without NCCP. The authors found that NCCP patients had more sleep problems, mental strain at work, stress at home, and negative life events as compared with the healthy group.

Gender differences related to psychological factors have also been observed in NCCP patients. Men reported less depression and trait anxiety than women. ${ }^{116}$

\section{Conclusion}

Our understanding of the epidemiology and natural course of NCCP remains relatively limited. Overall, the disease appears to be very common, without any gender predilection, and be associated with a good prognosis. More has been learned over the years about GERD, esophageal dysmotility, esophageal hypersensitivity and psychological comorbidity as important underlying mechanisms of NCCP. In patients with functional chest pain, the exact pathogenesis and the initial event or events that result in life-long chronic chest pain still remain poorly understood.

\section{References}

1. Jerlock M, Welin C, Rosengren A, Gaston-Johannson F. Pain characteristics in patients with unexplained chest pain and patients with ischemic heart disease. Eur J Cardiovasc Nurs 2007;6: 130-136.

2. Fass R, Navarro-Rodriguez T. Noncardiac chest pain. J Clin Gastroenterol 2008;42:636-646.

3. Fenster PE. Evaluation of chest pain: a cardiology perspective for gastroenterologists. Gastroenterol Clin North Am 2004;33:35-40.

4. Fenster PE, Sorrell VL. Evaluation of chest pain - a cardiology perspective for the gastroenterologist. In: Fass R, Eslick GD, eds. Noncardiac chest pain - a growing medical problem. San Diego: Plural Publishing 2007:15-23.

5. Ockene IS, Shay MJ, Alpert JS, Weiner BH, Dalen JE. Unexplained chest pain in patients with normal coronary arteriograms: a follow-up study of functional status. N Engl J Med 1980;303: 1249-1252.

6. Dumville JC, MacPherson H, Griffith K, Miles JN, Lewin RJ. Non-cardiac chest pain: a retrospective cohort study of patients who attended a Rapid Access Chest Pain Clinic. Fam Pract 2007; 24:152-157.

7. Sekhri N, Feder GS, Junghans C, Hemingway H, Timmis AD. How effective are rapid access chest pain clinics? Prognosis of incident angina and non-cardiac chest pain in 8762 consecutive patients. Heart 2007;93:458-463.

8. Robertson N, Javed N, Samani NJ, Khunti K. Psychological morbidity and illness appraisals of patients with cardiac and non-cardiac chest pain attending a Rapid Access Chest Pain Clinic: a longitudinal cohort study. Heart 2008;94:e12.

9. Galmiche JP, Clouse RE, Balint A, et al. Functional esophageal disorders. In: Drossman DA, Corazziari E, Delvaux M, Spiller RC, Talley NJ, Thompson WG, et al, eds. Rome III: The functional gastrointestinal disorders third edition. McLean, VA: Degnon Associates, Inc. 2006:369-418.

10. Mudipalli RS, Remes-Troche JM, Andersen L, Rao SS. Functional chest pain - esophageal or overlapping functional disorder. J Clin Gastroenterol 2007;41:264-269.

11. Nevens F, Janssens J, Piessens J, Ghillebert G, De Geest H, Vantrappen G. Prospective study on prevalence of esophageal chest pain in patients referred on an elective basis to a cardiac unit for suspected myocardial ischemia. Dig Dis Sci 1991;36:229-235.

12. Richter JE. Chest pain and gastroesophageal reflux disease. J Clin Gastroenterol 2000;30(3 suppl):S39-S41.

13. Ruigómez A, Massó-González EL, Johansson S, Wallander MA, García-Rodríguez LA. Chest pain without established ischaemic heart disease in primary care patients: associated comorbidities and mortality. Br J Gen Pract 2009;59:e78-e86.

14. Faybush EM, Fass R. Gastroesophageal reflux disease in noncardiac chest pain. Gastroenterol Clin North Am 2004;33:41-54. 
15. Potokar JP, Nutt DJ. Chest pain: panic attack or heart attack? Int J Clin Pract 2000;54:110-114.

16. Katerndahl DA, Trammell C. Prevalence and recognition of panic states in STARNET patients presenting with chest pain. J Fam Pract 1997;45:54-63.

17. Locke GR 3rd, Talley NJ, Fett SL, Zinsmeister AR, Melton LJ 3rd. Prevalence and clinical spectrum of gastroesophageal reflux: a population-based study in Olmstead County, Minnesota. Gastroenterology 1997;112:1448-1456.

18. Drossman DA, Li Z, Andruzzi E, et al. U.S. householder survey of functional gastrointestinal disorders. Prevalence, sociodemography, and health impact. Dig Dis Sci 1993;38:1569-1580.

19. Eslick GD. Noncardiac chest pain: epidemiology, natural history, health care seeking, and quality of life. Gastroenterol Clin North Am 2004;33:1-23.

20. Eslick GD, Jones MP, Talley NJ. Non-cardiac chest pain: prevalence, risk factors, impact and consulting - a population-based study. Aliment Pharmacol Ther 2003;17:1115-1124.

21. Chiocca JC, Olmos JA, Salis GB, et al. Prevalence, clinical spectrum and atypical symptoms of gastro-oesophageal reflux in Argentina: a nationwide population-based study. Aliment Pharmacol Ther 2005;22:331-342.

22. Wong WM, Lai KC, Lam KF, et al. Prevalence, clinical spectrum and health care utilization of gastro-oesophageal reflux disease in a Chinese population: a population-based study. Aliment Pharmacol Ther 2003;18:595-604.

23. Kennedy JW, Killip T, Fisher LD, Alderman EL, Gillespie MJ, Mock MB. The clinical spectrum of coronary artery disease and its surgical and medical management, 1974-1979. The Coronary Artery Surgery study. Circulation 1982;66(5 Pt 2):III16-III23.

24. Mousavi S, Tosi J, Eskandarian R, Zahmatkesh M. Role of clinical presentation in diagnosing reflux-related non-cardiac chest pain. J Gastroenterol Hepatol 2007;22:218-221.

25. Tew R, Guthrie E, Creed F, Cotter L, Kisely S, Tomenson B. A long-term follow-up study of patients with ischemic heart disease versus patients with nonspecific chest pain. J Psychosom Res 1995;39:977-985.

26. Wong WM, Risner-Adler S, Beeler J, et al. Noncardiac chest pain: the role of the cardiologist - a national survey. J Clin Gastroenterol 2005;39:858-862.

27. Wong WM, Beeler J, Risner-Adler S, Habib S, Bautista J, Fass R. Attitudes and referral patterns of primary care physicians when evaluating subjects with noncardiac chest pain - a national survey. Dig Dis Sci 2005;50:656-661.

28. Eslick GD, Talley NJ. Non-cardiac chest pain: predictors of health care seeking, the types of health care professional consulted, work absenteeism and interruption of daily activities. Aliment Pharmacol Ther 2004;20:909-915.

29. Richter JE, Bradley LA, Castell DO. Esophageal chest pain: current controversies in pathogenesis, diagnosis, and therapy. Ann Intern Med 1989;110:66-78.

30. Eslick GD, Talley NJ. Non-cardiac chest pain: squeezing the life out of the Australian healthcare system? Med J Aust 2000;173:233234.
31. Wielgosz AT, Fletcher RH, McCants CB, McKinnis RA, Haney TL, Williams RB. Unimproved chest pain in patients with minimal or no coronary disease: a behavioral phenomenon. Am Heart J 1984;108:67-72.

32. Potts S, Bass CM. Psychological morbidity in patients with chest pain and normal or near-normal coronary arteries: a long-term follow-up study. Psychol Med 1995;25:339-347.

33. Gurevitz O, Jonas M, Boyko V, Rabinowitz B, Reicher-Reiss $\mathrm{H}$. Clinical profile and long-term prognosis of women $<$ or $=50$ years of age referred for coronary angiography for evaluation of chest pain. Am J Cardiol 2000;85:806-809.

34. Launbjerg J, Fruergaard P, Hesse B, Jørgensen F, Elsborg L, Petri A. [The long-term prognosis of patients with acute chest pain of various origins.] Ugeskr Laeger 1997;159:175-179. [Danish]

35. Kisely S, Guthrie E, Creed F, Tew R. Predictors of mortality and morbidity following admission with chest pain. J R Coll Physicians Lond 1997;31:177-183.

36. Karlson BW, Wiklund I, Bengtson A, Herlitz J. Prognosis, severity of symptoms, and aspects of well-being among patients in whom myocardial infarction was ruled out. Clin Cardiol 1994;17:427-431.

37. Hallani H, Eslick GD, Cox M, Wyatt JM, Lee CH. Chest pain? Cause. Lancet 2004;363:452.

38. Ward BW, Wu WC, Richter JE, Hackshaw BT, Castell DO. Long-term follow-up of symptomatic status of patients with noncardiac chest pain: is diagnosis of esophageal etiology helpful? Am J Gastroenterol 1987;82:215-218.

39. Williams JF, Sontag SJ, Schnell T, Leya J. Non-cardiac chest pain: the long-term natural history and comparison with gastroesophageal reflux disease. Am J Gastroenterol 2009;104:2145-2152.

40. Wilhelmsen L, Rosengren A, Hagman M, Lappas G. "Nonspecific" chest pain associated with high long-term mortality: results from the primary prevention study in Göteborg, Sweden. Clin Cardiol 1998; 21:477-482.

41. Eslick GD, Talley NJ. Natural history and predictors of outcome for non-cardiac chest pain: a prospective 4-year cohort study. Neurogastroenterol Motil 2008;20:989-997.

42. Stahl WG, Beton RR, Johnson CS, Brown CL, Waring JP. Diagnosis and treatment of patients with gastroesophageal reflux and noncardiac chest pain. South Med J 1994;87:739-742.

43. Fass R, Fennerty MB, Ofman JJ, et al. The clinical and economic value of a short course of omeprazole in patients with noncardiac chest pain. Gastroenterology 1998;115:42-49.

44. Dickman R, Emmons S, Cui H, et al. The effect of a therapeutic trial of high-dose rabeprazole on symptom response of patients with non-cardiac chest pain: a randomized, double-blind, placebo-controlled, crossover trial. Aliment Pharmacol Ther 2005;22:547-555.

45. Bautista J, Fullerton H, Briseno M, Cui H, Fass R. The effect of an empirical trial of high-dose lansoprazole on symptom resonse of patients with non-cardiac chest pain - a randomized, double-blind, placebo-controlled, crossover trial. Aliment Pharmacol Ther 2004; 19:1123-1130.

46. Beedassy A, Katz PO, Gruber A, Peghini PL, Castell DO. Prior sensitization of esophageal mucosa by acid reflux predisposes to a reflux-induced chest pain. J Clin Gastroenterol 2000;31:121-124. 
47. DeMeester TR, O'Sullivan GC, Bermudez G, Midell AI, Cimochowski GE, O'Drobinak J. Esophageal function in patients with angina-type chest pain and normal coronary angiograms. Ann Surg 1982;196:488-498.

48. Pandak WM, Arezo S, Everett S, et al. Short course of omeprazole: a better first diagnostic approach to noncardiac chest pain than endoscopy, manometry, or 24-hour esophageal $\mathrm{pH}$ monitoring. J Clin Gastroenterol 2002;35:307-314.

49. Xia HH, Lai KC, Lam SK, et al. Symptomatic response to lansoprazole predicts abnormal acid reflux in endoscopy-negative patients with non-cardiac chest pain. Aliment Pharmacol Ther 2003; 17:369-377.

50. Singh S, Richter JE, Hewson EG, Sinclair JW, Hackshaw BT. The contribution of gastroesophageal reflux to chest pain in patients with coronary artery disease. Ann Intern Med 1992;117:824-830.

51. Hsia PC, Maher KA, Lewis JH, Cattau EL Jr, Fleischer DE, Benjamin SB. Utility of upper endoscopy in the evaluation of noncardiac chest pain. Gastrointest Endosc 1991;37:22-26.

52. Frøbert O, Funch-Jensen P, Jacobsen NO, Kruse A, Bagger JP. Upper endoscopy in patients with angina and normal coronary angiograms. Endoscopy 1995;27:365-370.

53. Dickman R, Mattek N, Holub J, Peters D, Fass R. Prevalence of upper gastrointestinal tract findings in patients with noncardiac chest pain versus those with gastroesophageal reflux disease (GERD)related symptoms: results from a national endoscopic database. Am J Gastroenterol 2007;102:1173-1179.

54. Smith JL, Opekun AR, Larkai E, Graham DY. Sensitivity of the esophageal mucosa to $\mathrm{pH}$ in gastroesophageal reflux disease. Gastroenterology 1989;96:683-689.

55. Hollerbach S, Bulat R, May A, et al. Abnormal cerebral processing of oesophageal stimuli in patients with noncardiac chest pain (NCCP). Neurogastroenterol Motil 2000;12:555-565.

56. Hu WH, Martin CJ, Talley NJ. Intraesophageal acid perfusion sensitizes the esophagus to mechanical distension: a Barostat study. Am J Gastroenterol 2000;95:2189-2194.

57. Sarkar S, Aziz Q, Woolf CJ, Hobson AR, Thompson DG. Contribution of central sensitisation to the development of non-cardiac chest pain. Lancet 2000;356:1154-1159.

58. Balaban DH, Yamamoto Y, Liu J, et al. Sustained esophageal contraction: a marker of esophageal chest pain identified by intraluminal ultrasonography. Gastroenterology 1999;116:29-37.

59. Pehlivanov N, Liu J, Mittal RK. Sustained esophageal contraction: a motor correlate of heartburn symptom. Am J Physiol Gastrointest Liver Physiol 2001;281:G743-G751.

60. Dogan I, Puckett JL, Padda BS, Mittal RK. Prevalence of increased esophageal muscle thickness in patients with esophageal symptoms. Am J Gastroenterol 2007;102:137-145.

61. Kushnir VM, Sayuk GS, Gyawali CP. Abnormal GERD parameters on ambulatory $\mathrm{pH}$ monitoring predict therapeutic success in noncardiac chest pain. Am J Gastroenterol 2010;105:1032-1038.

62. Katz PO, Dalton CB, Richter JE, Wu WC, Castell DO. Esophageal testing of patients with noncardiac chest pain or dysphagia. Results of three years' experience with 1161 patients. Ann Intern Med 1987;106:593-597.
63. Dekel R, Pearson T, Wendel C, De Garmo P, Fennerty MB, Fass R. Assessment of oesophageal motor function in patients with dyspepsia or chest pain - the Clinical Outcomes Research Initiative experience. Aliment Pharmacol Ther 2003;18:1083-1089.

64. Lam HG, Dekker W, Kan G, Breedijk M, Smout AJ. Acute noncardiac chest pain in a coronary care unit. Evaluation by 24-hour pressure and $\mathrm{pH}$ recording of the esophagus. Gastroenterology 1992;102:453-460.

65. Rencoret G, Csendes A, Henríquez A. [Esophageal manometry in patients with non cardiac chest pain.] Rev Med Chil 2006;134: 291-298. [Spanish]

66. Fass R. Chest pain of esophageal origin. Curr Opin Gastroenterol 2002;18:464-470.

67. Peters L, Maas L, Petty D, et al. Spontaneous noncardiac chest pain. Evaluation by 24-hour ambulatory esophageal motility and pH monitoring. Gastroenterology 1988;94:878-886.

68. Breumelhof R, Nadorp JH, Akkermans LM, Smout AJ. Analysis of 24-hour esophageal pressure and $\mathrm{pH}$ data in unselected patients with noncardiac chest pain. Gastroenterology 1990;99:1257-1264.

69. Achem SR, Kolts BE, Wears R, Burton L, Richter JE. Chest pain associated with nutcracker esophagus: a preliminary study of the role of gastroesophageal reflux. Am J Gastroenterol 1993;88:187192.

70. DiMarino AJ Jr, Allen ML, Lynn RB, Zamani S. Clinical value of esophageal motility testing. Dig Dis 1998;16:198-204.

71. Fass R, Naliboff B, Higa L, et al. Differential effect of long-term esophageal acid exposure on mechanosensitivity and chemosensitivity in humans. Gastroenterology 1998;115:1363-1373.

72. Handwerker HO, Reeh PW. Nociceptors: chemosensitivity and sensitization by chemical agents. In: Willis WD Jr, ed. Hyperalgesia and allodynia. New York: Raven Press 1992:107.

73. Barish CF, Castell DO, Richter JE. Graded esophageal balloon distention. A new provocative test for noncardiac chest pain. Dig Dis Sci 1986;31:1292-1298.

74. Richter JE, Barish CF, Castell DO. Abnormal sensory perception in patients with esophageal chest pain. Gastroenterology 1986;91: 845-852.

75. Rao SS, Gregersen H, Hayek B, Summers RW, Christensen J. Unexplained chest pain: the hypersensitive, hyperreactive, and poorly compliant esophagus. Ann Intern Med 1996;124:950-958.

76. Rao SS, Hayek B, Summers RW. Functional chest pain of esophageal origin: hyperalgesia or motor dysfunction. Am J Gastroenterol 2001;96:2584-2589.

77. Börjesson M, Pilhall M, Eliasson T, Norssell H, Mannheimer C, Rolny P. Esophageal visceral pain sensitivity: effects of TENS and correlation with manometric findings. Dig Dis Sci 1998;43: 1621-1628.

78. Lembo AJ. Visceral hypersensitivity in noncardiac chest pain. Gastroenterol Clin North Am 2004;33:55-60.

79. Mehta AJ, De Caestecker JS, Camm AJ, Northfield TC. Sensitization to painful distension and abnormal sensory perception in the esophagus. Gastroenterology 1995;108:311-319.

80. Sarkar S, Thompson DG, Woolf CJ, Hobson AR, Millane T, Aziz Q. Patients with chest pain and occult gastroesophageal reflux dem- 
onstrate visceral pain hypersensitivity which may be partially responsive to acid suppression. Am J Gastroenterol 2004;99:19982006.

81. Mujica VR, Mudipalli RS, Rao SS. Pathophysiology of chest pain in patients with nutcracker esophagus. Am J Gastroenterol 2001; 96:1371-1377.

82. Nasr I, Attaluri A, Hashmi S, Gregersen H, Rao SS. Investigation of esophageal sensation and biomechanical properties in functional chest pain. Neurogastroenterol Motil 2010;22:520-526, e116.

83. Hoff DA, Gregersen H, Ødegaard S, Hjertaker BT, Hatlebakk JG. Sensation evoked by esophageal distension in functional chest pain patients depends on mechanical stress rather than on ischemia. Neurogastroenterol Motil 2010;22:1170-1176, e309-e311.

84. Bass C, Wade C, Hand D, Jackson G. Patients with angina with normal and near normal coronary arteries: clinical and psychosocial state 12 months after angiography. Br Med J (Clin Res Ed) 1983;287:1505-1508.

85. Bass C, Wade C. Chest pain with normal coronary arteries: a comparative study of psychiatric and social morbidity. Psychol Med 1984;14:51-61.

86. Channer KS, Papouchado M, James MA, Rees JR. Anxiety and depression in patients with chest pain referred for exercise testing. Lancet 1985;2:820-823.

87. Costa PT Jr. Influence of the normal personality dimension of neuroticism on chest pain symptoms and coronary artery disease. Am J Cardiol 1987;60:20J-26J.

88. McCroskery JH, Schell RE, Sprafkin RP, Lantinga LJ, Warner RA, Hill N. Differentiating anginal patients with coronary artery disease from those with normal coronary arteries using psychological measures. Am J Cardiol 1991;67:645-646.

89. Flugelman MY, Weisstub E, Galun E, et al. Clinical, psychological and thallium stress studies in patients with chest pain and normal coronary arteries. Int J Cardiol 1991;33:401-408.

90. Mayou R, Bryant B, Forfar C, Clark D. Non-cardiac chest pain and benign palpitations in the cardiac clinic. Br Heart J 1994;72: 548-553.

91. Chignon JM, Lepine JP, Ades J. Panic disorder in cardiac outpatients. Am J Psychiatry 1993;150:780-785.

92. Tennant C, Mihailidou A, Scott A, et al. Psychological symptom profiles in patients with chest pain. J Psychosom Res 1994;38: 365-371.

93. Wong WM, Lam KF, Cheng C, et al. Population based study of noncardiac chest pain in southern Chinese: prevalence, psychosocial factors and health care utilization. World J Gastroenterol 2004;10: 707-712.

94. Clouse RE, Lustman PJ. Psychiatric illness and contraction abnormalities of the esophagus. N Engl J Med 1983;309:1337-1432.

95. Cannon RO 3rd, Benjamin SB. Chest pain as a consequence of abnormal visceral nociception. Dig Dis Sci 1993;38:193-196.

96. Fleet RP, Dupuis G, Marchand A, Burelle D, Arsenault A, Beitman BD. Panic disorder in emergency department chest pain patients: prevalence, comorbidity, suicidal ideation, and physician recognition. Am J Med 1996;101:371-380.

97. Demiryoguran NS, Karcioglu O, Topacoglu H, et al. Anxiety dis- order in patients with non-specific chest pain in the emergency setting. Emerg Med J 2006;23:99-102.

98. Jones M, Lewis A. Effort syndrome. Lancet 1941;237:813-818.

99. Huffman JC, Pollack MH. Predicting panic disorder among patients with chest pain: an analysis of the literature. Psychosomatics 2003;44:222-236.

100. Alexander PJ, Prabhu SG, Krishnamoorthy ES, Halkatti PC. Mental disorders in patients with noncardiac chest pain. Acta Psychiatr Scand 1994;89:291-293.

101. Carter CS, Maddock RJ. Chest pain in generalized anxiety disorder. Int J Psychiatry Med 1992;22:291-298.

102. Dammen T, Ekeberg O, Arnesen H, Friis S. Personality profiles in patients referred for chest pain. Investigation with emphasis on panic disorder patients. Psychosomatics 2000;41:269-276.

103. Husser D, Bollmann A, Kühne C, Molling J, Klein HU. Evaluation of noncardiac chest pain: diagnostic approach, coping strategies and quality of life. Eur J Pain 2006;10:5 1-55.

104. Stollman NH, Bierman PS, Ribeiro A, Rogers AI. $\mathrm{CO}_{2}$ provocation of panic: symptomatic and manometric evaluation in patients with noncardiac chest pain. Am J Gastroenterol 1997;92:839-842.

105. Cooke RA, Anggiansah A, Wang J, Chambers JB, Owen W. Hyperventilation and esophageal dysmotility in patients with noncardiac chest pain. Am J Gastroenterol 1996;91:480-484.

106. Lantinga LJ, Sprafkin RP, McCroskery JH, Baker MT, Warner RA, Hill NE. One-year psychosocial follow-up of patients with chest pain and angiographically normal coronary arteries. Am J Cardiol 1988;62:209-213.

107. Hotopf M, Mayou R, Wadsworth M, Wessely S. Psychosocial and development antecedents of chest pain in young adults. Psychosom Med 1999;61:861-867.

108. Dammen T, Arnesen H, Ekeberg O, Friis S. Psychological factors, pain attribution and medical morbidity in chest-pain patients with and without coronary artery disease. Gen Hosp Psychiatry 2004;26: 463-469.

109. Katon W, Hall ML, Russo J, et al. Chest pain: relationship to psychiatric illness to coronary arteriographic results. Am J Med 1988; 84:1-9.

110. Eken C, Oktay C, Bacanli A, et al. Anxiety and depressive disorders in patients presenting with chest pain to the emergency department: a comparison between cardiac and non-cardiac origin. J Emerg Med 2010;39:144-150.

111. Cormier LE, Katon W, Russo J, Hollifield M, Hall ML, Vitaliano PP. Chest pain with negative cardiac diagnostic studies. Relationship to psychiatric illness. J Nerv Ment Dis 1988;176:351-358.

112. García-Campayo J, Rosel F, Serrano P, et al. Different psychological profiles in non-cardiac chest pain and coronary artery disease: a controlled study. Rev Esp Cardiol 2010;63:357-361.

113. Beitman BD, Basha I, Flaker G, et al. Atypical or nonanginal chest pain. Panic disorder or coronary artery disease? Arch Intern Med 1987; 147:1548-1552.

114. Cheng C, Wong WM, Lai KC, et al. Psychosocial factors in patients with noncardiac chest pain. Psychosom Med 2003;65:443449.

115. Jerlock M, Kjellgren KI, Gaston-Johansson F, et al. Psychosocial 
profile in men and women with unexplained chest pain. J Intern Med 2008;264:265-274.

116. Fagring AJ, Gaston-Johannson F, Kjellgren KI, Welin C. Unex- plained chest pain in relation to psychosocial factors and health-related quality of life in men and women. Eur J Cardiovasc Nurs 2007;6:329-336. 